\title{
PRINSIP BELAJAR MENGAJAR DALAM ANALEKTA YANG TERKANDUNG PADA FILM KUNGFU PANDA DAN KUNGFU PANDA 2
}

\author{
Agustinus Sufianto $^{1}$; Patricia $^{2}$ \\ Chinese Department, Faculty of Humanities, BINUS University \\ Jln. Kemanggisan Ilir III No. 45, Kemanggisan-Palmerah, Jakarta Barat 11480 \\ 1agustlay@gmail.com; 2patricia_ye@hotmail.co.id
}

\begin{abstract}
The Analects is one of the famous books from China which records Confucius' teachings. Kungfu Panda and Kungfu Panda 2 are two famous animation films from America. After seeing these movies, there are some similar values that can be found between the movies and The Analects, especially in education field. The writer limited the scope into teaching and learning principles. The writer defined 2 main issues. First is to explain the correlation between Kungfu Panda and Kungfu Panda's teaching and learning principles with The Analects. Second is to understand those principles and its application in our daily lives. This research method is library research. The results stated that there are some correlation between Kungfu Panda, Kungfu Panda 2, and The Analects. Analyzing the correlation will help us to understand more about Confucius' teaching, especially in education field.
\end{abstract}

Keywords: Kungfu Panda, Kungfu Panda 2, The Analects, Teaching and Learning Principles

\begin{abstract}
ABSTRAK
Analekta adalah salah satu kitab yang sangat terkenal dari China yang mencatat ajaran-ajaran dari Konfusius. Kungfu Panda dan Kungfu Panda 2 adalah dua film yang terkenal dari Amerika. Setelah melihat kedua film ini, ada kesamaan nilai yang dapat ditemukan antara kedua film dengan Analekta, khususnya dalam bidang pendidikan. Penulis membatasi ruang lingkup menjadi prinsip belajar dan mengajar. Sedangkan masalah utama dijabarkan menjadi 2 bagian. Pertama, apa saja korelasi antara prinsip belajar mengajar Kungfu Panda dan Kungfu Panda 2 dengan Analekta. Kedua, untuk mengerti makna dan penerapannya dalam kehidupan sehari-hari. Tujuan penelitian yang pertama yaitu menyimpulkan korelasi antara Kungfu Panda, Kungfu Panda 2, dan Analekta. Tujuan kedua yaitu supaya kita dapat menerapkan prinsip-prinsip tersebut dalam kehidupan sehari-hari. Metode penelitian menggunakan studi pustaka. Hasil penelitian yaitu terdapat korelasi antara Kungfu Panda, Kungfu Panda 2, dan Analekta, dari segi prinsip belajar dan mengajar. Menganalisis korelasi tersebut membantu kita untuk lebih memahami makna dari ajaran Konfusius, khususnya dalam bidang pendidikan.
\end{abstract}

Kata kunci: Kungfu Panda, Kungfu Panda 2, Analekta, Prinsip Belajar dan Mengajar 


\section{PENDAHULUAN}

Analekta merupakan sebuah kitab terkenal dari China yang isinya mencatat isi dari ajaran Konfusius. Sedangkan Kungfu Panda dan Kungfu Panda 2 adalah film animasi yang terkenal dari Amerika. Setelah menyaksikan kedua film ini, penulis mengamati adanya kesamaan nilai-nilai dalam film tersebut dengan Analekta, khususnya dari segi prinsip belajar dan mengajar.

Penulis membatasi ruang lingkup menjadi prinsip belajar dan mengajar. Selain itu, penulis juga menjabarkan dua masalah utama. Pertama, apa saja korelasi antara prinsip belajar mengajar Kungfu Panda dan Kungfu Panda 2 dengan Analekta. Kedua, untuk mengerti makna dan penerapannya dalam kehidupan sehari-hari. Tujuan pertama penelitan yaitu menyimpulkan korelasi antara Kungfu Panda, Kungfu Panda 2 dan Analekta. Tujuan kedua yaitu supaya kita dapat menerapkan prinsip-prinsip tersebut dalam kehidupan sehari-hari. Metode penelitian menggunakan studi pustaka. Hasil penelitian yaitu terdapat korelasi antara Kungfu Panda, Kungfu Panda 2, dan Analekta, dari segi prinsip belajar dan mengajar. Menganalisis korelasi tersebut membantu kita untuk lebih memahami makna dari ajaran Konfusius, khususnya dalam bidang pendidikan.

Berdasarkan penelitian dari Xie Hehua tentang makna nilai pendidikan Konfusius dalam Analekta dan penelitian dari Ma Huizhen tentang makna nilai pendidikan dalam Analekta beserta standar penerapannya, dapat dilihat bahwa memang Analekta kaya akan nilai-nilai pendidikan yang masih relevan untuk diterapkan dalam dunia pendidikan pada masa sekarang. Dengan metode studi pustaka yang dilakukan mereka, penulis dapat lebih menelaah kajian literatur yang mereka gunakan untuk meneliti topik tersebut.

Penulis akan membahas lebih lanjut tentang korelasi antara prinsip belajar mengajar antara film dan kitab tersebut, serta menguraikan contoh aplikasi dari prinsip-prinsip tersebut dalam kehidupan sehari-hari, khususnya untuk aplikasi dalam dunia pendidikan.

\section{METODE PENELITIAN}

Metode penelitian yang dilakukan adalah metode kualitatif dengan tipe studi pustaka. Mestika Zed (2008) menyatakan bahwa beberapa hal yang akan menjadi ciri khas penulis dalam penggunaan metode kepustakaan adalah: penulis akan meneliti langsung dari buku, artikel, dan jenis naskah lainnya; data pustaka yang akan dijadikan sumber dan bahan penelitian adalah jenis data pustaka yang mempunyai korelasi dengan penelitian; data pustaka yang akan dijadikan bahan penelitian bersifat sumber sekunder, yang berarti penulis mendapatkan data-data tersebut tidak langsung dari lapangan; data pustaka tersebut tidak dibatasi oleh ruang dan waktu. Data tersebut adalah data tetap, di mana data-data tersebut tidak akan berubah (Zed, 2008: 4-5).

Media dalam penelitian ini adalah Film Kungfu Panda dan Kungfu Panda 2. Kedua film ini dipilih karena memiliki nilai pendidikan yang amat kental. Terdapat banyak adegan mengenai tujuan, motivasi, serta proses belajar, juga banyak adegan mengenai hubungan antara guru-murid, dan juga antarsesama murid. Selain itu, media yang digunakan adalah Buku Lunyu Zhuyi dan Kongzi de huofa. Kedua buku ini dipilih karena dalam buku tersebut, terdapat terjemahan dari bahasa China klasik ke bahasa China modern. Analekta adalah kitab pada masa China klasik, di mana ada gaya bahasa dan tata bahasa yang berbeda dalam penulisan karya sastra. Agar dapat mengerti arti kalimat-kalimat tersebut, perlu diterjemahkan terlebih dahulu dalam bahasa China modern, sebelum diterjemahkan dalam bahasa Indonesia. Kedua buku ini memiliki penjelasan yang mendetail serta jelas, dijelaskan 
istilah per kata, sehingga akan lebih mudah mengerti makna dari Analekta dan menghindari salah pengertian.

Instrumen pertama penelitian ini adalah teori prinsip belajar dan mengajar Konfusius di dalam Analekta. Di dalam Analekta terdapat banyak prinsip belajar dan mengajar dari Konfusius. Menurut Konfusius, proses belajar terbagi menjadi 4 tahap, yaitu belajar, analisis, latihan, dan praktik. Terdapat 2 ciri khas dalam teori dari nilai pendidikan Konfusius, yaitu penerapan pendidikan moral dan sasaran dari pendidikan moral itu sendiri. Konfusius lebih menekankan pendidikan moral selain pendidikan intelektual. Setiap muridnya diharapkan dapat menjadi seseorang yang memiliki pengetahuan, sikap, kesetiaan, dan dapat dipercaya orang lain. Falsafah 'ren' juga tetap menjadi prinsip dasar dalam aspek pendidikan.

Konfusius juga menekankan prinsip belajar yang terus berkelanjutan. Belajar tidak hanya dilakukan di sekolah, tetapi dalam kehidupan sehari-hari ada banyak hal yang juga dapat dipelajari. Prinsip belajar dan mengajar dalam Analekta mencakup sikap dalam belajar dan mengajar, cara mengajar, juga hubungan antara guru dan murid.

Prinsip yin cai shi jiao adalah inti dari pengalaman mengajar Konfusius. Prinsip ini berarti mengajar murid sesuai dengan bakat, watak, dan minat. Setiap murid memiliki keunikan masingmasing. Untuk mencapai hasil belajar yang maksimal, seorang guru perlu mengerti kondisi muridnya, dan menggunakan metode yang paling tepat untuk mengajar.

Prinsip qi fa you dao mengandung arti bahwa seorang guru harus memiliki kompetensi untuk membina muridnya agar menjadi orang yang memiliki intelektual dan moral. Untuk dapat membina muridnya dengan baik, guru harus memberi teladan, serta memiliki kesabaran terhadap murid. Dalam prinsip di atas juga terkandung prinsip ju yi fan san, artinya mampu membuat analogi atau perbandingan. Dalam proses belajar, guru perlu mendorong murid untuk memiliki penalaran yang baik, juga pemahaman yang mendalam akan apa yang telah dipelajari. Konfusius juga menekankan prinsip bahwa belajar itu harus dilakukan dengan senang hati dan tidak menjadikan belajar sebagai beban. Ia juga menentang cara menghafal mati suatu ilmu. Konfusius lebih menginginkan muridnya dapat menggunakan kata-kata dan membuat analogi sendiri dari pemahaman para masing-masing murid, akan apa yang telah mereka pelajari.

Prinsip xue si bing zhong mempunyai makna bahwa belajar harus diimbangi juga dengan analisis. Sebagai seorang murid, sangat penting untuk memiliki kemampuan membuat analogi, membandingkan bermacam-macam pengetahuan yang ia dapatkan dan mempertimbangkan berbagai prinsip serta nilai. Seorang guru memiliki tanggung jawab untuk membimbing muridnya agar memiliki kemampuan analisis yang baik.

Prinsip you bo fan yue mempunyai makna bahwa seorang murid perlu 'banyak mendengar, banyak melihat' harus memiliki banyak pengetahuan dan pengalaman yang luas, baru bisa berhasil beradaptasi dengan masyarakat. Sekarang ini, seorang murid harus belajar dari berbagai macam sumber agar ia kaya dengan pengetahuan sehingga saat menjumpai masalah, ia dapat menganalisis, dan membuat analogi tentang permasalahan tersebut dengan tepat (ju yi fan san).

Prinsip yan chuan shen jiao, shu li shi de dian fan bermakna bahwa belajar adalah sebuah proses yang berkelanjutan. Seumur hidup kita merupakan pembelajaran tanpa henti. Ada juga prinsip, "san ren xing, bi you wo shi yan." Ini berarti di dalam satu kelompok, ada seorang yang menjadi guru atau pemimpin bagi orang lain.

Prinsip wen gu zhi xin mengulangi pelajaran, lalu setelah direnungkan dan dipahami, mampu menciptakan ide baru dari apa yang telah dipelajari (dapat membuat inovasi). 


\section{Kompilasi Data}

Penulis akan memberikan plot dari media, dan karena media yang digunakan salah satunya adalah film, maka akan diberikan juga tokoh/ karakter penting dalam film tersebut. Plot media (Sinopsis cerita Kungfu Panda dan Kungfu Panda 2): Film Kungfu Panda diputar di bioskop pada tahun 2008. Inti cerita film berkisah tentang seekor panda bernama Po mewujudkan mimpinya menjadi pahlawan naga, dengan tantangan harus mengalahkan Tailung yang amat kuat. Film Kungfu Panda 2 diputar di bioskop pada tahun 2011, 3 tahun setelah kesuksesan film pertamanya. Dalam Kungfu Panda 2, dikisahkan Po yang telah berhasil menjadi pahlawan naga, kini harus menghadapi tantangan yang lebih berat. Selain harus mengalahkan Lord Shen, Po juga harus berjuang mengalahkan ketakutannya akan masa lalu yang menyakitkan. Kedua film ini sukses menjadi box office di Amerika, dan seluruh dunia, termasuk juga di China. Meskipun film ini adalah produksi negara Amerika, di dalamnya terkandung bermacam-macam unsur budaya dan nilai-nilai negara China, khususnya dalam bidang pendidikan. Tokoh-tokoh penting dalam film ini:

Po: panda lucu yang pada sifatnya santai, namun ia memiliki keteguhan dan kesungguhan dalam mencapai cita-citanya. Keingintahuannya tinggi, ia juga seorang yang pantang menyerah. Ada sisi dalam diri Po di mana ia terkadang percaya diri, dan terkadang ragu-ragu. Dari sini keberanian Po untuk membuat pilihan-pilihan yang tepat memberikan contoh bagaimana seorang yang awalnya biasa saja, dapat berubah jauh lebih baik karena keputusan tepat yang ia buat.

Master Shifu: guru Po yang mengajari Po ilmu Kungfu. Master Shifu adalah seorang guru yang bijaksana. Meskipun pada awalnya ia tidak menyukai Po karena ia menganggap Po tak mampu menjadi pendekar, pada akhirnya ia dapat memandang Po dari segi positif, menerima dan membimbingnya sampai menjadi pendekar tangguh yang berjasa bagi banyak orang.

Teman-teman seperjuangan Po (Tigress, Monkey, Mantis, Viper, Crane): mereka adalah teman-teman satu tim Po dalam mengalahkan musuh. Mereka memiliki karakter yang berbeda, di mana dari sini mereka dilukiskan bekerja sama dan saling membantu dalam menghadapi musuh.

Master Oogway: guru dari Master Shifu yang karakternya sangat bijaksana. Kata-katanya mampu memberikan pengaruh positif kepada pendengarnya.

Tai Lung dan Lord Shen: merupakan tokoh antagonis. Tai Lung adalah musuh Po dalam Kungfu Panda, sedangkan Lord Shen dikisahkan telah membunuh keluarga Po. Lord Shen baru muncul dalam Kungfu Panda 2.

Mr. Ping: ayah angkat Po. Ia sangat protektif dan menyayangi Po seperti anaknya sendiri.

Soothsayer: peramal yang meramalkan kejatuhan Lord Shen dalam Kungfu Panda 2. Ia pernah berkata bahwa suatu hari nanti akan ada pahlawan hitam dan putih yang mengalahkan Lord Shen. Namun sayang, ia tak mampu meramalkan bahwa setelah itu, Lord Shen bergegas menyerang desa tempat Po lahir. Soothsayer menyelamatkan Po saat Po kalah bertarung dengan Lord Shen.

Analekta adalah sebuah prosa klasik yang mencatat ajaran dan pemikiran dari Konfusius. Kumpulan prosa yang terdiri dari 20 bab ini dicatat oleh para murid dari Konfusius. Menurut buku yang berjudul Buku-Buku yang Mengubah Dunia karangan Andrew Taylor, Analekta yang ditulis sekitar abad 5 SM merupakan salah satu buku dari 50 buku yang telah mengubah perkembangan sejarah manusia. 
Qian Xun (2010), mengatakan bahwa "Intisari dari Analekta adalah membahas mengenai bagaimana seseorang bisa menjadi pribadi yang berkualitas” Qian Xun (2010:10). Andrew Taylor menyatakan bahwa visi Analekta adalah membangun masyarakat yang dapat menggunakan hak dan kewajiban mereka untuk saling membantu satu sama lain.

\section{Analisis}

Di dalam Analekta sendiri mengandung banyak ajaran baik secara ajaran moral, filosofi dan lain-lain. Akan tetapi, yang difokuskan disini adalah prinsip belajar mengajar dari Konfusius dalam kitab Analekta yang terdapat dalam film Kungfu Panda dan Kungfu Panda 2. Pembahasan akan difokuskan dalam menganalisis ajaran / nilai yang terkait dengan pendidikan (belajar). Setelah itu, menganalisis lebih lanjut nilai-nilai yang terkandung dalam adegan film Kungfu Panda, karena pada adegan tersebut terdapat dialog-dialog yang dapat ditelaah maknanya. Adegan-adegan dalam film tersebut sarat dengan dialog yang bermakna dalam hal belajar-mengajar, juga dalam hubungan antara guru dan murid dan juga antara sesama murid.

Berikut adalah contoh lain tentang nilai pendidikan dari Konfusius dalam film. 我非生而知之 者 (wǒ fêi shēng ér zhīzhī zhè). Kalimat ini bermakna bahwa ketika seorang lahir , orang tersebut tidak serta-merta jadi pandai , tapi perlu belajar terlebih dahulu. Untuk menjadi pandai atau menjadi seorang ahli maka orang tersebut perlu belajar sungguh-sungguh. Di dalam film, Po awalnya adalah seorang penjual mie. Ia harus belajar keras untuk bisa menjadi pendekar, tidak dari lahir langsung menguasai jurus-jurus hebat seperti pendekar pada umumnya, tapi ada proses yang harus ia jalani dari tidak menguasai apa-apa menjadi menguasai jurus-jurus yang harus dimiliki seorang pendekar. Dalam film digambarkan banyak adegan tentang sulitnya proses belajar yang harus dijalani oleh Po untuk menguasai Kungfu. Meski banyak terselip adegan humor, pesan yang terkandung tetap tersampaikan dengan baik.

Hasil yang diharapkan adalah agar penelitian ini dapat menjadi referensi bagi para pembaca untuk memahami nilai-nilai pendidikan (prinsip belajar dan mengajar) dalam Analekta yang terkandung pada film Kungfu Panda dan Kungfu Panda 2. Diharapkan dengan hasil penelitian ini, para pembaca dapat lebih mudah untuk mengaplikasikan nilai-nilai pendidikan yang terkandung di film Kungfu Panda dan Kungfu Panda 2 dalam kehidupan sehari-hari.

\section{HASIL DAN PEMBAHASAN}

Ketika menonton film Kungfu Panda, kita dapat menemukan bahwa di dalamnya terkandung banyak nilai budaya China. Di luar unsur-unsur budaya seperti bentuk bangunan rumah, kungfu, makanan, kostum para tokoh, bubuk mesiu, dan lain-lain, kita juga dapat melihat nilai-nilai ideologi dari bangsa China. Salah satu ideologi yang jelas terlihat adalah falsafah "ren". Di sini terlihat bahwa pada dasarnya pesan utama yang ingin disampaikan dalam film ini adalah tentang kebaikan yang menang melawan kejahatan. Dalam film ini, nilai "ren" juga ditonjolkan dengan semangat kepahlawanan dari Po untuk membela kebenaran. Salah satu contoh penerapan nilai "ren" yang lain adalah persahabatan dan kekeluargaan yang erat dari Po dan 5 sekawan.

Bentuk penerapan yang lain adalah memiliki hati yang mau memaafkan (salah satu bentuk kasih). Master Shifu menyimpan kepahitan dalam hatinya karena Tailung yang awalnya dia percaya ternyata malah berbalik melawannya. Hal ini menyebabkan dia sulit menerima kehadiran Po karena Master Shifu memiliki trauma yang dalam yang diakibatkan oleh Tailung. 
Kungfu Panda juga memberikan kita pelajaran bahwa pendidikan moral sangatlah penting. Selain itu, kepercayaan diri juga menjadi salah satu pesan penting yang disampaikan melalui alur cerita Kungfu Panda karena ternyata pendidikan moral berpengaruh terhadap pembentukan karakter seorang pendekar di dalam Kungfu Panda.

Ada satu kalimat yang sangat bagus dari film Kungfu Panda sekuel pertama, yaitu "Yesterday is history, tomorrow is a mystery, but today is a gift, that is why it's called present." Di dalam Analekta 18.5 ada sebuah kalimat, "wang zhe bu ke jian, lai zhe you ke zhui", yang kalau diartikan secara sederhana isinya bermakna bahwa kita tidak bisa mengubah masa lalu, juga tidak bisa meramalkan masa depan. Jadi kita harus fokus pada hari ini dengan cara melakukan yang terbaik pada setiap kesempatan yang ada.

Pada sekuel kedua juga terdapat satu adegan yang kembali mengingatkan kita akan prinsip "wang zhe bu ke jian" ini. Saat Po terluka parah akibat serangan dari Lord Shen, ia ditolong oleh Soothsayer. Sang peramal ini mengingatkan Po dengan perkataan: "Your story may not such have a happy beginning. But it doesn't make who you are. It is the rest of your story, who you choose to be." Kalimat ini bermakna "Kisah hidupmu tidak memiliki awal yang bahagia. Tetapi itu tidak menentukan siapa jati dirimu. Engkaulah yang menentukan kelanjutan kisah hidupmu dengan memilih akan menjadi seperti apakah dirimu.”

Hubungan antara Prinsip belajar mengajar Analekta dengan Film Kungfu Panda dan Kungfu Panda 2 adalah sebagai berikut: Prinsip yin cai shi jiao dalam film ini adalah dalam Kungfu Panda, terdapat adegan bagaimana Master Shifu melatih Po menjadi seorang yang menguasai Kungfu. Awalnya, Master Shifu menggunakan cara yang keras sampai membuat Po putus asa. Namun, setelah Master Shifu mengubah caranya mengajar termasuk cara pandangnya terhadap Po maupun metode pengajaran yang digunakan, pada akhirnya Po dapat menjadi seorang pekungfu andal yang pada akhirnya bisa menyelamatkan para penduduk dari ancaman Tailung.

Prinsip qi fa you dao dapat dilihat dalam Film Kungfu Panda, ada 2 tokoh guru yaitu Master Oogway dan Master Shifu. Dikisahkan bahwa Master Oogway adalah guru yang amat bijak. Ia meninggalkan teladan yang amat baik kepada muridnya, Master Shifu. Hal ini membuat Master Shifu mampu menyerap ajaran gurunya dengan baik. Kita juga dapat melihat Master Shifu yang juga berusaha menjadi guru yang baik bagi Po. Kita dapat melihatnya dari prinsip yin cai shi jiao yang dilakukan Shifu. Sebagai seorang guru, penting untuk menetapkan harapan yang tidak terlalu tinggi terhadap murid. Akan tetapi, di sisi lain, guru juga harus menaruh kepercayaan terhadap kemampuan muridnya. Terlihat jelas saat Master Shifu baru mulai akan melatih Po, ia sama sekali tidak percaya bahwa Po mampu. Sedangkan saat mendidik Tai Lung, dari awal Master Shifu sudah menaruh kepercayaan yang sangat besar kepadanya. Dari 2 keadaan ini - kepada yang satu tidak percaya sama sekali, sedangkan kepada yang satu sangat percaya adalah 2 keadaan yang sangat kontras. Segala sesuatu harus diberikan tepat pada porsinya. Apapun jika berlebihan akan memiliki efek negatif.

Pendidikan moral yang baik sangat diperlukan. Sikap tegas juga diperlukan saat mendidik. Ketika Master Shifu menanamkan harapan yang terlalu tinggi pada Tai Lung tanpa memberikan ajaran bagaimana ia harus bersikap seandainya sesuatu terjadi tidak seperti yang ia inginkan, maka Tai Lung pun menjadi ambisius dan harus mendapatkan apapun yang ia inginkan. Di sini Master Shifu meminta maaaf kepada Tai Lung untuk kesalahannya yang dulu terlalu menaruh harapan besar pada Tai Lung. Kita dapat melihat sikap kejujuran guru terhadap sang murid. Berkaitan dengan "zhizhi wei zhizhi, buzhi wei buzhi", yang berarti seseorang yang mengatakan mengetahui sesuatu atau tidak mengetahui haruslah selaras dengan yang benar-benar dengan ia ketahui atau tidak ketahui, maka Master Shifu juga menerapkan kejujuran tersebut dengan meminta maaf karena ia mengetahui kesalahannya.

Pada prinsipnya bagaimana cara seorang guru membina muridnya itulah yang akan menentukan bagaimana kelak muridnya pada masa depan. Namun, sebagai seorang murid, kita juga 
harus kritis. Guru adalah manusia biasa yang masih bisa melakukan kesalahan. Master Shifu meminta maaf pada Tai Lung, ini menunjukkan bahwa ada beberapa konsep yang pernah salah dalam pemikiran Shifu. Maka sebagai murid, kita harus punya kemampuan membuat analogi yang baik (ju yi fan san), bukan hanya bisa menghafal atau menguasai materi, tetapi juga bisa mempertimbangkan yang benar dan salah. Hal ini penting, karena nantinya pada saat masalah datang, di sanalah juga terdapat ujian untuk menentukan benar atau salah.

Salah satu contoh keberhasilan guru dalam membina murid yang terlihat dalam film Kungfu Panda adalah keberhasilan Master Shifu dalam melatih Po menjadi dragon warrior. Master Shifu juga berhasil membuat proses belajar mengajar menjadi menyenangkan (le xue), dan Po bisa menikmati belajar Kungfu sambil berebut bakpao. Selain itu, Master Shifu juga memotivasi Po untuk tidak menyerah sampai ia bisa menguasai kungfu. Selain berhasil mendidik Po, sebenarnya Master Shifu juga berhasil mendidik murid-muridnya yang lain, yaitu 5 sekawan. Namun, hubungan Po dan Master Shifu lebih ditonjolkan di dalam film Kungfu Panda dan Kungfu Panda 2 sebagai contoh dinamika hubungan guru dan murid di dunia nyata.

Prinsip xue si bing zhong dan you bo fan yue dapat dilihat pada Film Kungfu Panda, saat Master Shifu merasa sangat panik karena mendengar berita Tai Lung akan kabur dari penjara, ia tidak mampu berpikir jernih. Melihat hal ini, Master Oogway sebagai guru dari Master Shifu, mengatakan kalimat-kalimat yang merupakan nasihat agar Master Shifu terlebih dahulu menenangkan pikirannya. Barulah Master Shifu mampu melihat permasalahan ini dari sudut pandang yang berbeda, tidak serumit saat ia panik. Dari adegan ini terlihat bahwa seorang guru perlu menuntun muridnya agar bisa belajar menganalisis dan mempertimbangkan pengambilan keputusan. Master Oogway menggunakan perumpamaan untuk menasihati Master Shifu agar tenang. Pikiran yang tenang justru akan membantunya untuk menemukan solusi dari masalah yang ada.

Dalam hal ini, Master Oogway adalah seorang guru yang pandai membuat analogi (ju yi fan san). Ia juga menggunakan hal-hal sederhana di sekitar (contohnya air kolam) untuk memberikan perumpamaan kepada Master Shifu. Master Oogway menekankan bahwa pikiran yang tenang, pertimbangan yang matang, dan analisis yang baik akan benar-benar membantu menemukan solusi yang tepat.

Menurut Konfusius, untuk dapat memiliki kemampuan analisis yang baik, kita harus banyak mendengar dan banyak melihat, jadi wawasan kita lebih bertambah luas. Dari film Kungfu Panda kita juga dapat melihat bahwa Po, tidak hanya belajar dari Master Shifu, tapi juga dari Master Oogway, Mr. Ping, Soothsayer, dan juga teman-teman yang lainnya. Banyak pihak telah memberikan kontribusi kepada Po sehingga pada akhirnya semua itu digunakan sebagai acuan untuk maju lebih baik lagi.

Prinsip yan chuan shen jiao, shu li shi de dian fan dapat dilihat pada saat Po memimpin teman-temannya dalam bertarung. Kita bisa melihat prinsip "san ren xing, bi you wo shi yan" dalam adegan ini. Pada salah satu adegan, dikisahkan Po memiliki kelemahan, yaitu ketakutan akan masa lalunya. Tigress yang melihat hal ini pun melarang Po untuk pergi melawan Lord Shen, karena Lord Shen berhubungan langsung dengan masa lalu Po. Selama Po belum bisa menghadapi ketakutannya, Lord Shen dapat dengan mudah membunuh Po. Dalam satu kelompok, ada salah satu orang yang menjadi guru atau pemimpin bagi orang lain, tetapi terkadang sang pemimpin juga mempunyai kelemahan. Kita mungkin dapat mempelajari kelebihannya, namun kita juga harus peka terhadap kekurangan atau kesalahan yang ia lakukan dan tidak terseret dalam kesalahan yang diperbuat oleh seorang pemimpin.

Selain itu di dalam film juga diajarkan bahwa belajar merupakan proses yang berkesinambungan. Po harus belajar lebih dalam jurus selanjutnya yang didemonstrasikan Master Shifu dan jurus ini memerlukan tingkat pemahaman yang lebih dalam atas diri sendiri. Master Shifu menekankan bahwa di dalam hati juga harus ada nilai kebaikan (de) dengan melupakan kesakitan atau 
trauma pada masa lalu, sehingga kita mempunyai kesadaran dan kekuatan untuk berubah. Oleh karena itu, kita belajar untuk tidak merasa cepat puas ketika kita menjadi pemimpin dan harus terus-menerus belajar lebih baik lagi.

Prinsip wen gu zhi xin terlihat dalam Kungfu Panda 2, saat adegan Po mulai menguasai gerakan yang melambangkan inner peace. Di sini kita dapat melihat penerapan prinsip wen gu zhi xin. Saat adegan pertarungan terakhir dengan Lord Shen, Po pun mampu menggunakan gerakan inner peace ini untuk menangkal serangan meriam dari Lord Shen. Bahkan hal ini membuat Master Shifu terkejut akan kemampuan muridnya. Sebelumnya, tidak ada yang berhasil menangkal serangan meriam dari Lord Shen. Dari sini dapat dilihat bahwa Po menyerap baik-baik yang telah ia pelajari, lalu pada akhirnya ia dapat menghasilkan suatu jurus baru yaitu menangkal meriam dengan gerakan memainkan embun.

Penulis menggolongkan aplikasi dari prinsip belajar mengajar Analekta menjadi aplikasi dalam kehidupan sehari-hari dan aplikasi dalam dunia pendidikan. Aplikasi dalam kehidupan seharihari dapat kita pelajari dari nilai kebaikan sampai memperjuangkan mimpi. Dari penjabaran karakter tokoh dalam kedua film, serta nilai-nilai yang terkandung di dalamnya, kita dapat melihat bahwa, "Apa yang kelihatan sepertinya begitu, bukanlah yang sebenarnya. Satu-satunya cara untuk mengetahui karakter seseorang lebih dalam adalah melalui pilihan-pilihan yang mereka buat di bawah tekanan” (Robert McKee, 1997:103). Masalah akan menyingkapkan karakter sebenarnya dari orang tersebut. Pada dasarnya pembinaan karakter itu diperlukan, dan sebaiknya dilakukan sejak usia dini. Saat kita sudah berhasil menerima diri sendiri, menjadi seorang pribadi yang utuh, kita akan mampu menyikapi berbagai macam permasalahan dan konflik dengan bijak. Untuk menjadi bijak, manusia itu harus dibina dan menerima pendidikan yang bermutu.

Aplikasi dalam dunia pendidikan dapat kita lihat dari bagaimana manfaat pendidikan dalam hidup seseorang. McKee (1997:110-111) menyatakan bahwa, "Pendidikan akan mempersiapkan kita kelak ke dalam pengalaman emosional kehidupan yang mampu menyingkap banyak persepsi baru." Pendidikan dan intelegensi yang baik akan mengarahkan seseorang untuk membuat keputusan yang tepat dalam segala permasalahan yang ia temui. Keberhasilan proses belajar di dalam dunia pendidikan pada dasarnya merupakan hasil dari seberapa efektif hubungan timbal balik dan kontribusi yang diberikan oleh guru dan murid. Kegiatan belajar tidak boleh dijadikan beban berat, namun menjadi tahapan-tahapan yang dapat dinikmati oleh kedua pihak, baik guru maupun muridnya.

\section{SIMPULAN}

Melalui analisis korelasi antara Kungfu Panda dan Kungfu Panda 2 dengan Analekta membantu kita lebih memahami makna dari ajaran Konfusius. Meski Analekta merupakan karya sastra China klasik, isinya tetap relevan untuk diterapkan pada masa sekarang. Saat kita belajar dari teladan dan kesalahan para tokoh dalam film ini, hal tersebut dapat membantu kita menjadi orang yang lebih baik lagi, serta memberikan teladan yang baik dan pengaruh positif kepada orang lain, khususnya dalam bidang pendidikan.

Dari analisis ini, penulis menyimpulkan bahwa salah satu cara sederhana untuk memandang hidup yaitu dengan melihatnya sebagai kesempatan, tanggung jawab, dan pilihan. Akan tetapi, kesempatan itu harus digunakan dengan penuh tanggung jawab, ditunjukkan dengan membuat pilihan yang paling tepat untuk setiap permasalahan yang muncul sehari-hari. Untuk membuat pilihan yang tepat, seseorang harus dibekali pendidikan yang baik. Jadi, saat menghadapi berbagai macam masalah, orang itu mampu menggunakan rasionya untuk membuat keputusan. Ini sesuai dengan ajaran Konfusius di dalam Analekta yang memfokuskan pendidikan untuk membina seseorang menjadi 
manusia yang berkualitas melalui proses belajar yang efektif. Baik guru maupun murid harus bekerja sama agar tujuan pembelajaran dapat tercapai maksimal. Diharapkan melalui penjelasan mengenai prinsip belajar mengajar Konfusius dalam Analekta dapat menjadi referensi kepada guru dan siswa di dalam proses belajar mengajar.

\section{DAFTAR PUSTAKA}

a.n. (2011). Gongfu Xiongmao 2 Kungfu Panda 2 (2011) Zhongyingwen duizhao zi. Retrieved April 30, 2012, from http://www.doc88.com/p-59896714915.html.

a.n. (2007). Imagi Announces Strategic Alliance for Gatchaman and Astro Boy Toy Development. Retrieved May 21, 2012, from http://www.animenewsnetwork.com/press-release/2007-0807/imagi-announces-strategic-alliance-for-gatchaman-and-astro-boy-toy-development. 20078-7/2012-5-21

a.n. (2008). Gongfu Xiongmao Kungfu Panda. Retrieved April 22, 2012, from http://movie.mtime.com/44740/

a.n. (2008). Kung Fu Panda Breaks Chinese Box-Office Records. Retrieved May 21, 2012, from http://www.telegraph.co.uk/news/worldnews/asia/china/2268139/Kung-Fu-Panda-breaksChinese-box-office-records.html.

a.n. (2009). Lunyu shi shei xie de. Retrieved April 30, 2012, from http://zhidao.baidu.com/question/81578474.html

a.n. (2009). Tantao Lunyu ganshou Kongzi de jiaoyu fangfa. Retrieved April 30, 2012, from http://www.12edu.cn/lunwen/yyjy/200912/401580.shtml

a.n. (2010). Gongfu Xiongmao Zhongyingwen juben. Retrieved April 30, 2012, from http://www.doc88.com/p-94551004013.html

a.n. (2011). "Gongfu Xiongmao 2"rongru geng duo de Zhongguo yuansu- 'Kong Fu Panda 2' incorporates more Chinese elements. Retrieved May 21, 2012, from http://thinkingchinese.com/index.php?page_id=291

a.n. Cultural China. Retrieved May 21, 2012, from http://kaleidoscope.cultural china.com/en/188Kaleidoscope11096.html. 2012-5-21.

Buku Pintar EYD, Bahasa dan Sastra Indonesia. 2011. Yogyakarta: Cabe Rawit.

Cobb, M. (Producer) , \& Yuh, J. (Director). (2011). Kungfu Panda 2 [DreamWorks Picture \& Pasific Data Images]. United States: Paramount Pictures.

Cobb, M. (Producer), \& Osborne, M., \& Stevenson, J. (Directors). (2008). Kungfu Panda [DreamWorks Picture \& Pasific Data Images]. United States: Paramount Pictures.

Daily news staff writing. (2008, June 1). 'Kung Fu Panda' gets Cuddly. Retrieved May 21, 2012, from http://www.nydailynews.com/entertainment/movies/kung-fu-panda-cuddly-article-1.296608 
Han Jiantang. (2005). Zhongguo wenhua. Beijing: Beijing Yuyan Wenhua Daxue Chubanshe. http://www.moviesonline.ca/movienews_14790.html Entertainment.

Hui Liming. (2006). Lunyu yu dangdai jiaoyu. Retrieved April 30 ${ }^{\text {th }}$, from http://edu.gansudaily.com.cn/system/2006/11/07/010177306.shtml.

Li Haibin. (2007). Lunyu zhong de jiaoyu sixiang. Retrieved April 30, 2012, from http://chinese.cersp.com/sJsys/zZyfz/200711/5515.html.

Liang Jie. (2004). Lunyu zhong de jiaoyu sixiang ji xianshi yiyi (wang you lai gao). Retrieved April 30,2012, from, http://www.ruiwen.com/news/17732.htm.

Ma Huizhen. (2007). Cong Lunyu kan Kongzi de jiaoyu sixiang jiqi zhuiqiu de renge biaozhun. Weipu zhuanye jiansuo jiaoyu хие. 26 (153), 133-136.

Ma Yinchun. (2006). Lunyu de zhihui. Beijing: Zhongguo Wuzi Chubanshe.

McKee, R. (1997). Story: Substance, Structure, Style, and The Principles of Screenwriting. New York: Harper

Mu Zi. (2011). Pepatah China Kuno untuk generasi modern. Jakarta: Elex Media Komputindo.

Qian Xun. (2010). Kongzi de huofa. Shenyang: Liaoning Renmin Chubanshe.

Roberts, S. Jack Black Interview, Kung Fu Panda. Retrieved May 21, 2012, from http://www.moviesonline.ca/movienews 14790.html.

Sun Qinshan. (2011). Lunyu zhuyi. Nanjing: Fenghuang Chubanshe.

Tang, M.C. (2004). Kisah-kisah Kebijaksanaan China klasik: refleksi bagi para pemimpin. (Vivi Sutanto, penterjemah). Jakarta: Gramedia Pustaka Utama. (naskah asli terbit tahun 2000).

Taylor, A. (2011). Buku-Buku yang mengubah dunia. (O.V.Y.S. Damos S., penterjemah). Jakarta: Erlangga. (naskah asli terbit tahun 2008).

Walliman, N.S.R. (2004). Your Undergraduate Dissertation: the essential guide for success. London: SAGE.

Wang Minghua, Hu Zhuju. (2008). Qianxi Lunyu de jiaoxue yuanze he fangfa. Retrieved May 21, 2012, from http://www.chinakongzi.org/gxdt/200801/t20080111 3153157.htm

Wang, D. (2010, June 19). From Confucius to The Great Wall: Chinese Cultural Influence on Colonial North America. Retrieved May 1, 2012, from http://www.ajrc.jp/docs/20100619_AJforum19_Dr.Wang.pdf

Wijana, I. D. P. (2004). Kartun: studi tentang permainan bahasa. Yogyakarta: Ombak.

Xie Hehua. (2009). Kongzi de jiaoyu sixiang ji Xianshi yiyi. Wenxue jiaoyu (xia). (12), 62-63.

Xu Zongcai. (2005). Gudai Hanyu: di yi ce. Beijing: Beijing Yuyan Wenhua Daxue Chubanshe.

Yang Pingyi. (2005). Zhongguo ren de shenghuo zhihui. Xi’an: Shanxi Shifan Daxue Chubanshe. 
Yeong, W. (2011). Implikasi Ajaran Konfusius terhadap Falsah Pendidikan Negara. Diakses 15 Mei 2012 dari http://www.scribd.com/doc/59412375/7/Ajaran-Confucius-14.

Zed, M. (2008). Metode penelitian kepustakaan (Ed. 2). Diakses 16 November 2011 dari http://books.google.co.id/books?id=iIV8zwHnGo0C\&pg=PA4\&lpg=PA4\&dq=metode+studi+ kepustakaan\&source=bl\&ots=ncfh5LZ5V\%20k\&sig=4yAL5j6OZ3oQi7uUyYlUIZ1FqQ\&hl =id\&ei=cAzGTrqIDtGzrAfoqPWwDg\&sa=X\&oi=book_result\&ct=result\&resnum=8\&sqi=2 \&ved $=0 \mathrm{CEgQ6AEwBw} \# \mathrm{v}=$ onepage $\& \mathrm{q}=$ =metode $\% 20$ studi\%20kepustakaan $\& \mathrm{f}=$ false

Zhao Changzheng. (2007). Zhongguo wenxue zhuanye Hanyu jiaocheng. Beijing: Beijing Daxue Chubanshe.

Zhou Siyuan. (2005). Zhongguo gudai wenxue shigang. Beijing: Beijing Yuyan Wenhua Daxue Chubanshe 